\title{
PERTUNJUKAN SENDRATARI BAHOELA DAN KINI DALAM ACARA HORAS SAMOSIR FIESTA DI KABUPATEN SAMOSIR
}

\author{
Oleh \\ TRI MEYANI MALAU \\ Prodi Pendidikan Musik
}

\begin{abstract}
The Bahoela and Today Sendratari Show at Horas Samosir Fiesta Event in Samosir Regency. Faculty of Arts and Languages. State University of Medan. 2015. This research is aimed to know how the Bahoela and Today Sendratari Show that will be held and the way of the event management from the beginning until the end is. In the discussion of this research, the researcher used related theory to the topic of writing, such as theory of show, theory of sendratari and theory of management. The research methodology used in this research was descriptive qualitative. To complete the data in this research, the researcher conducted a field observation, videos, interviewing and documentation. The population in this research was the whole involved committee, the performers and the audiences. After all the data were collected, they were analysed then to answer all the researcher's questions. The data analysis was done by using qualitative data technique which was described in phases in writing form. After the analysis was done, it was found that the event management in order to make the event run well, it was started form planning, determining the structure, preparing, conducting, making a responsibility report, evaluating the result, effects, redeveloping/replanning and the show presented music, drama and dance which told about occurrences in Bahoela Era and Today.
\end{abstract}

Keywords: Bahoela Sendratari, Horas Samosir Fiesra Event in Samosir Regency, Show 


\section{PENDAHULUAN}

Suku Batak Toba adalah salah satu dari ragam suku yang ada di Indonesia yang masih menyimpan sejarah dan masih sangat kental dengan adat serta kebudayaannya seperti yang terdapat di kabupaten Samosir Kabupaten yang yang terbentuk oleh letusan gunung Toba yang sangat dasyat ini masih menyimpan banyaknya sejarah yang menarik perhatian dunia, sejarah singkat yang menjelaskan mengapa Pulau Samosir berada diatas Danau dan bagaimana proses terbentuknya Danau Toba, berawal dari letusan gunung Toba purba sebanyak 3 ( tiga) kali, letusan pertama menghasilkan kaldera ( kawah ) di Timur danau Toba yaitu porsea dan sekitarnya 840 tahun yang lalu dan letusan kedua membentuk kaldera ((kawah ) di Utara danau Toba yaitu haranggaol sekitar 500 tahun yang lalu.

74.000 tahun yang lalu yang sebagian meterilnya terbuang sehingga membentuk kaldera Toba, kaldera itu berangsur-angsur terisi oleh air hujan selama ratusan tahun lamanya itulah yang membentuk danau Toba. Diproses akhir tenaga magma yang tersisa mengakibatkan terjadinya pengangkatan lapisan kulit bumi dari dasar danau kepermukaan sehingga terbentuklah Pulau Samosir, setelah beberapa tahun kemudian seiring berjalannya waktu pulau itu sudah banyak dihuni oleh masyarakat yang sangat sangat primitif bahkan belum mengenal agama sekalipun, tetapi mereka mulai memanfaatkan yang ada disekitar seperti Martonun ((menenun ulos) membuat ramuramuan yang dipercayai bisa mengobati segala penyakit. Ramuan yang diracik juga diakui sebagai media untuk meminta perlindungan dan berkat yang berlimpah kepada Oppu Mulajadi Nabolon yang kini disebut dengan Tuhan Yang Maha Kuasa dan sedikit dari ramuan tersebut dibuat dalam beberapa cawan dan kemudian diletak diatas kepala para kaum wanita dan siap di percikkan kepada orang yang ada disekitar dengan cara membawanya sambil manortor ( tortor cawan ) seseorang berkeliling memberi berkat yang telah diminta dan 
selebihnya menari di tempat sambil menyusun cawan satu persatu karna cawan yang di gunaka $\mathrm{n}$ sebanyak tujuh setiap orangnya.

Walaupun masyarakat

Samosir tinggal di atas danau yang memiliki keindahan alam indah, tapi karena masyarakat yang pada zaman dulu belum mengerti untuk membentuk atau lebih mengindahkan lagi, mereka terbuka untuk orang baru dan masyarakat disana sangat menerima perubahan karena perubahan itu bukan untuk memperburuk tetapi diyakini bisa lebih memajukan kesejahteraan masyarakat Toba yang ada disana, lantunan lagu yang mengekspresikan kecintaan mereka terhadap tanah kelahiran dan kecintaan mereka terhadap negeri yang mereka akui sebagai kepingan surga itu lama kelamaan tercipta dengan indahnya dan keindahan Danau Toba dan Samosir kini telah mendunia.

Kabupaten Samosir genap berumur 10 tahun pada tujuh Januari 2014 dan selama 10 tahun itu juga bukan hal yang mudah untuk mewujudkan mimpi samosir yang ingin menjadikan samosir daerah tujuan wisata yang ingin menarik perhatian seluruh dunia. Salah satu upaya meningkatkan kesadaran masyarakat samosir akan pentingnya menjalin kebersamaan untuk samasama menjaga penuh kebudayaan dan sejarah, Kabupaten Samosir selalu mengadakan pesta tahunan yaitu "Horas Samosir Fiesta" dimana acara ini selalu mengangkat ceritacerita rakyat Samosir dan selalu mengadakan macam-macam perlombaan untuk meningkatkan semangat para kaum muda. Hampir setiap tahun Samosir merayakan Horas Samosir Fiesta dengan tema yang berbeda-beda agar lebih menarik perhatian penonton baik bagi masyarakat itu sendiri maupun pengunjung yang datang dari luar Samosir, seperti dua tahun lalu Horas Samosir Fiesta atau yang disingkat dengan HSF mengambil tema, Samosir menuju daerah wisata yang Inovatif dan Kreatif, dalam acara ini samosir pertama sekali memperkenalkan GEOPARK ((Taman Bumi ) dimana didalam taman ini pengunjung dapat melihat langsung situasi yang menggambarkan proses terjadinya 
danau Toba, kejadian-kejadian alam serta kehidupan masyarakat samosir dahulu kala baik itu manduda,martonun dan monortor akan dibangun dan disahkan oleh Presdien Susilo Bambang Yudiyono.

Bulan Desember tahun 2014 akan diadakan lagi Horas Samosir Fiesta dimana untuk tahun ini mengangkat sejarah awal terbentuknya Samosir dan danau Toba serta perkembangan yang dicapai samosir sampai pada saat ini. Dengan tema "BAHOELA dan KINI" sedikit berbeda dengan tahuntahun sebelumnya dimana samosir fiesta tahun ini tidak menggunakan musik modern untuk mengiringi penari atau panortor seperti keyboard ataupun kaset, untuk pertunjukan tahun ini lebih dominan kepada alat musik tradisionalnya dan dimainkan oleh anak-anak yang berumur 10-17 tahun, pertunjukan tari cawan atau tortor cawan, tortor martonun dan tortor manomba, pertunjukan world drum juga tidak akan lepas dari acara ini begitu juga dengan penampilan marsada yang akan memeriahkan acara dan menghibur para pengunjung yang hadir pada acara Horas Samosir Fiesta pada bulan Desember yang akan datang.

Dengan uraian yang diatas penulis tertarik untuk meneliti bagaimana pertunjukan sendratari Bahoela dan Kini dalam acara Horas Samosir Fiesta 2014. Untuk membatasi penelitian saya fokuskan penelitian di Kabupaten Samosir. Sehingga hasil penelitian ini dapat lebih memperdalam pengetahuan tentang bagaimana mengelola sebuah karya yang akan dipentaskan ataupun pertunjukan yang akan berlangsung.

Tujuan yang ingin dicapai dalam penelitian ini ialah sebagai berikut

1. Menjelaskan pertunjukan sendratari yang akan diadakan pada acara Horas Samosir Fiesta 2014

2. Mendiskripsikan pengelolaan acara dari awal, pertengahan sampai akhir pada pertunjukan Samosir Fiesta

\section{Landasan Teori}

Untuk membahas pertunjukan Sendratari Bahoela dan Kini dalam acara Horas Samosir Fiesta di Kabupaten Samosir 
penulis menggunakan beberapa teori yaitu teori pertunjukan, teori sendratari, dan teori pengelolaan

\section{Lokasi dan Waktu Penelitian}

Sesuai dengan judul penelitiaan (Pertunjukan Sendtaratari Bahoela dan Kini dalam Acara Horas Samosir Fiesta di Kabupaten Samosir maka, penelitian dilaksanakan pada tim Event Organizer dan para pengisi acara pertunjukan tersebut. Waktu penelitian sudah sebelum pelaksanaan seminar proposal dengan mengambil data berupa foto dan video tetapi akan dikuatkan dalam bentuk wawancara yang akan berlangsung pada bulan Maret-April 2015.

\section{Populasi dan Sampel}

\section{Populasi}

Maka yang akan menjadi Populasi dalam penelitian ini adalah seluruh panitia yang terlibat, pengisi acara dan penonton dalam pertunjukan Horas Samosir Fiesta.

\section{Sampel}

Sampel dalam penelitian ini sebanyak 4 orangyang terdiri dari ketua pelaksana, penasehat pelaksana, sekretaris dan pimpinan event organizer ( pimpinan produksi) Funkgora Production.

\section{Teknik Pengumpulan Data}

Teknik pengumpulan data yang dilakukan adalah sebagai berikut:

1. Pengamatan Observasi

2. Wawancara

3. Dolumentasi

4. Studi Kepustakaan

\section{Teknik Analisis Data}

Dalam penelitian ini data yang digunakan adalah analisis deskriptif kualitatif yang terkumpul melalui observasi lapangan, wawancara, dokumentasi dan studi kepustakaan. Semua data yang diperoleh dilapangan dicatat, kemudian hasil akan dianalisis dengan secermat mungkin. Hasil olahan data dan analisis data tersebut disususn secara sistematis dengan teknik deskriptif kualitatif, sehingga hasilnya dapat dilihat dalam satu bentuk laporan ilmiah atau skripsi.

ISI

Letak Geografis Kabupaten Samosir 
Letak Geografis Secara Geografis Kabupaten Samosir terletak pada $2024^{6}-2025^{6}$ Lintang Utara dan $98021^{`}$ - 990 55“ BT. Secara Administratif Wilayah Kabupaten Samosir diapit oleh tujuh Kabupaten, yaitu di sebelah Utara berbatasan dengan Kabupaten Karo dan Kabupaten Simalungun di sebelah Timur berbatasan dengan Kabupaten Toba Samosir; di sebelah Selatan berbatasan dengan Kabupaten Tapanuli Utara dan Kabupaten Humbang Hasundutan dan di sebelah Barat berbatasan dengan Kabupaten Dairi dan Kabupaten Pakpak Barat.

Iklim dan Cuaca Sebagai daerah pertanian dan sebagian penduduknya hidup danmenggantungkan dengan pertanian, curah hujan merupakan salah satu faktor eksternal yang menentukankeberhasialn pertanian penduduk.

Luas Wilayah Kabupaten Samosir memiliki luas wilayah $2.069,05 \mathrm{~km}^{2}$ yang terdiri dari luas daratan $1.444,25 \mathrm{Km}^{2}$ dan perairan Danau Toba $624,80 \quad \mathrm{~km}^{2}$ Secara administratifKabupaten
Samosirterdiridari 9 Kecamatan, 111desa dan 6 Kelurahan.

\section{Pertunjukan sendratari Bahoela dan Kini dalam Acara Horas Samosir Fiesta.}

Acara dan pertunjukan yang diadakan disamosir merupakan agenda tahunan yang dilakukan untuk menguatkan kreativitas para kaula muda baik itu yang bergerak dibidang seni dan juga olahraga. Dimana pada kesempatan ini Horas Samosir Fiesta memilih Bahoela dan Kini menjadi tema untuk mengangkat kembali sejarah dari Gunung Toba, Samosir dan sejarah dari bangso batak. Pagelaran ini selain untuk mengangkat cerita rakyat bangsa batak pada awalnya juga untuk mempromosikan potensi pariwisata kabupaten samosir.

Pagelaran Sendratari Bahoela dan Kini diadakan pada bulan Agustus 2014 di Bukit Beta desa Tuk-tuk Siadong Kecamatan Simanindo Kabupaten Samosir. Alasan mengapa tim pelaksana memilih Bukit Beta sebagai tempat untuk diadakannya pertunjukan ialah karena tempatnya lebih strategis, 
lebih luas dan tempat ini adalah daerah dimana para pengunjung dari luar negeri banyak dijumpai sehingga akan sangat mudah untuk memikat perhatian para pengunjung luar negeri jika mendengar dan menyaksikan musik maupun tari tradisional Batak Toba.

Mengingat semua para pengisi acara bukan yang berdomisili dilokasi pertunjukan maka pada pukul 08.00 pagi WIB semua yang berperan dalam acara baik itu panitia juga pengisi acara berangkat dari pangururan menuju tuktuk siadong, setibanya dilokasi pada pukul 09.00 WIB tim EO mengingatkan kepada semua yang terkait untuk memperhatikan setiap alat yang sudah ditanggung jawabkan kepada tiam group baik itu property apa yang dipakai, costum dan keperluan make up artis serta kelengkapankelengkapan diatas panggung mulai dari letak alat musik dan lighthing semua dipersiapkan sejak pagi. Dibawah ini ialah sususan acara dan para pengisui acara pada malam 02 agustus 2015 pukul 19.00
SUSUNAN ACARA HORAS SAMOSIR FIESTA SAMOSIR BAHOELA DAN KINI TUKTUK,02 AGUSTUS 2014

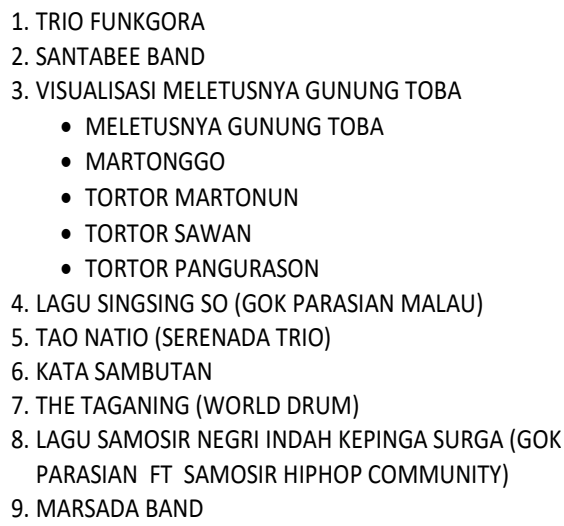

Organized by

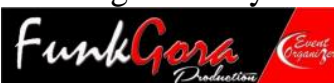

\section{Pengelolaan Acara}

Dalam melakukan penelitian Pertunjukan Sendratari Bahoela dan Kini dalam acara Horas Samosir Fiesta 2014 penulis juga dibantu oleh Bapak Charles Malau selaku pimpinan event organizer pada acara Sendaratari Bahoela dan Kini yang diadakan di Bukit Beta Tuk-tuk Siadong Kecamatan Simanindo. Berdasarkan hasil observasi dan wawancara langsung yang dilakukan pada tanggal 29 Maret 2015 di studio Funkgora Production milik Bapak Charles Malau. Bapak Charles Malau 
menjelaskan bahwa dalam

melakukan sebuah pertunjukan harus berpedoman pada tahaptahap serta langkah-langkah seperti dibawah ini

1. Perencanaan

2. Menetapkan struktur

3. Prepare

4. Pelaksanaan

5. Evaluasi hasil

6. Dampak

7. Pengembangan/ perencanaan

\section{PENUTUP}

\section{Kesimpulan}

A.

Dari hasil penelitian dan pembahasan dapat ditarik beberapa kesimpulan sebagai berikut:

1. Sistem manajemen pada pertunjukan sendratari Bahoela dan Kini dalam Horas Samosir Fiesta meliputi: perencanaan, penetapan struktur atau tugas seorang EO, prepare (persiapan), pelaksanaan, laporan pertanggung jawaban, evaluasi hasil, dampak, pengembangan hasil.

a. Proses perencanaan pertunjukan sendratari Bahoela dan Kini meliputi: penentuan tema acara, penentuan sasaran acara untuk siapa, menentukan tujuan acara untuk apa, menentukan waktu yang tepat, menentukan tempat yang tepat.

b. Menetapkan struktur, fungsi dan tugas EO dalam tahap ini tugas EO dalam pertunjukan sendratari Bahoela dan Kini meliputi: menentukan projek manajer, menentukan stage manajer, show director, menentukan yang menjadi public facility, 
menentukan pnue

coordinator,

menentukan lo

liaison oficer artis

dan tamu vip,

mengurutkan

konsep kegiatan,

dan

mengalokasikan

dana.

c. Proses prepare

pertunjukan

sendratari Bahoela

dan Kini meliputi

artis, mc dan

panitia.

d. Proses pelaksanaan

pertunjukan

sendratari Bahoela

dan Kini diawali

dengan musik

opening pada pukul

19.30, acara inti

yaitu pagelaran

sendratari,

penampilan bintang

tamu yaitu Marsada

Band dan ditutup

oleh Bupati

Kabupetan Samosir

yaitu Ir. Mangindar
Simbolon pada

pukul 00.30

e. Proses pembuatan

surat laporan

pertanggung

jawaban kepaa

dinas terkait ialah

dimulai dengan

perincian biaya

yang diperlukan

saat proses latihan

hingga sampai

terlaksananya acara

pagelaran,

mencantumkan

foto, faktur atau

bon setiap

pembelian produk

untuk setiap

keperluan sebagai

bukti dokumentasi

agar laporan lebih

akurat.

f. Pada tahap evaluasi

hasil maka para

panitia atau semua

yang terkait akan

mengadakan

breafing setelah

acara selesai guna

untuk melaporkan 


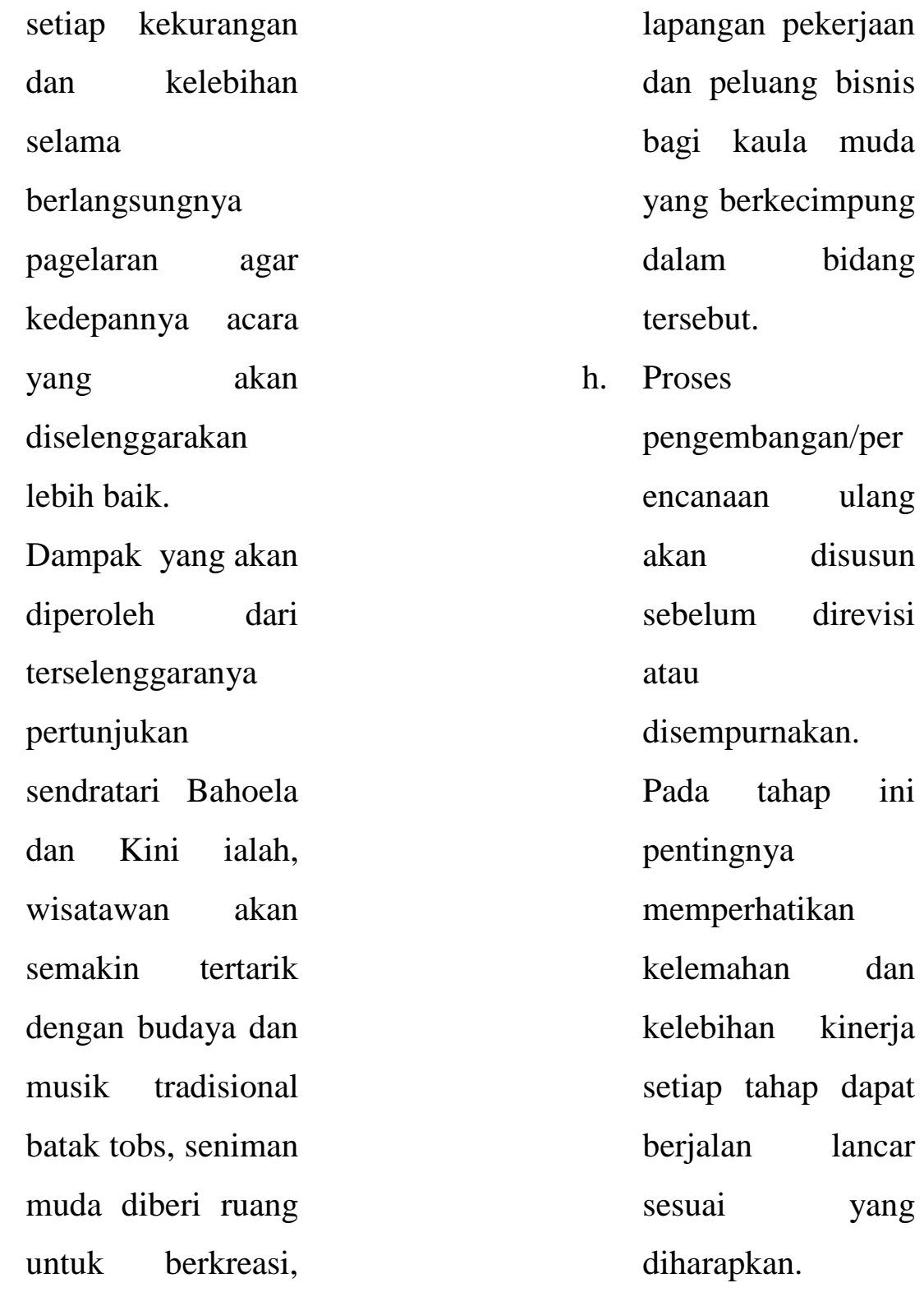

pelaksana EO juga akan dikenal oleh masyarakat luas Saran dengan hasil kinerja yang sudah terlaksana sehingga berdampak terhadap tersedianya

1. Setelah terselenggaranya pertunjukan sendratari Bahoel dan Kini semoga kedepannya para 
masyarakat semakin

menghargai dan

mendukung setiap agenda

pemerintahan terhadap

peningkatan pariwisata

Kabupaten Samosir

dengan pagelaran-

pagelaan budaya agar

setiap orang yang terkait

dalam acara baik itu

pengisi acara dan panitia

akan lebih semangat dan

menampilkan yang

terbaik.

2. Perlu adanya komunikasi kepada para operator sound system terkait gambaran atau bentuk acara yang akan berlangsung dari awal, pertengahan sampai akhir agar operator sound system tidak kewalahan dalam mengoperatorkan microphone, kejelasan suara sampai sejauh mana dan yang lain-lainnya.

3. Kegiatan pertunjukan dan pagelaran yang mengangkat budaya dan sejarah seperti Sendratari
Bahoela dan Kini patut

dipertahankan

(ditindaklanjuti) dan akan

menampilkan pagelaran

yang mengangkat tema

yang lebih menarik.

\section{DAFTAR PUSTAKA}

Arikunto. 2006. “ Prosedur Penelitian Suatu Pendekatan Praktik ". Jakarta: PT Rineka Cipta

Edi Setiadyati. 1986. “ Budaya Indonesia Kajian Arkeologi, Seni dan Sejarah”. Jakarta: RajaGrafindo Persada

Griffin. 1990. “ Dasar-dasar Pengelolaan”. Jakarta: Erlangga

Jamalus. 1998. “ Panduan Pengajaran Musik Melalui Pengalaman Musik ". Jakarta: Proyek Pengembangan Lembaga Tenaga Kependidikan

Kiki Amalia Hasibuan. 2012. Peranan Musik Dalam Pementasan “ Door ” Ditaman Budaya Sumatera Utara ". 
Skripsi. Universitas Negeri

Medan

Lydia Sitra Lestari. 2011. “

Sendratari Elang Ngelakak

Dikecamatan Karang Baru

Kabupaten Aceh Tamiang ".

Skripsi. Universitas Negeri

Medan

Marlita Situmorang. 2008.

Peranan Musik Dalam Seni Pertunjukan Teater Ditaman Budaya Sumatera Utara ". Skripsi. Universitas Negeri Medan

Muhammad TakarI, Heristira Dewi. 2008. "Budaya Musik Melayu dan Tari Melayu Sumatera Utara". Medan, Indonesia: USU press

Mulyana, Deddy, 2003. “ Metodologi Penelitian Kualitatif - Paradikma Baru Ilmu Komunikasi dan Ilmu Sosial Lainnya ". Bandung: PT. Remaja Rosdakarya
Prof. Dr. Sugiono. 2010. “Metode Penelitian Kuantitatif Kualitatif Dan R\&D ". Bandung: Alfabeta

Prof. Dr. Sugiono. 2012. “Metode Penelitian Pendidikan ". Bandung: Alfabeta

Pamadhi, Hadjar. 2008. Materi Pokok Pendidikan Seni. Jakarta: Universitas Terbuka.

Rahmat Elieser Hasugian. 2014. “ Manajemen Seni Pertunjukan Pada Acara Pesona Budaya Sumatera Utara 2013 ”. Skripsi. Universitas Negeri Medan

Rose Lee Goldburge. 2013. Performance Art Studies". Jakarta: Erlangga

Sudibyo. 2013. “ Pementasan Teater". Universitas Pendidikan Indonesia

Sudjana. 2007. Pengolahan Acara. Jakarta: Bumi Aksara

Supranto. 2004 “ Metode Penelitian ". Jakarta: Ghalia Indonesia 
Sutrisno Hadi. 1986. “ Metodologi Research," Jilid 1, 2. UGM

http:

//id.wikipedia.orang/seni_pertunjuka $\mathrm{n}$

https://www.scribd.com/mobile/...65

783 